\title{
BARCELONA SAO PAULO, TAN LEJOS TAN CERCA. A PROPÓSITO DEL LIBRO BARCELONA Y SAO PAULO CARA A CARA. PROCESOS METROPOLITANOS A LA HORA DE LA GLOBALIZACIÓN.
}

\author{
Gerardo Sánchez Delgado*
}

En esta ocasión los profesores Carles Carreras y Ana F.A. Carlos, exponen uno de los productos de la importante relación investigadora que existe hace tiempo entre los equipos de geografía urbana de la Universidad de Barcelona y la Universidad de Sao Paulo, en un conjunto de estudios y reflexiones de óptica ínterescalar, acerca de las transformaciones de las metrópolis, en el escenario de la reestructuración económica mundial denominada globalización. Un aporte teórico y metodológico, prioritario para el entendimiento de las dinámicas económicas, sociales y espaciales de las ciudades de Barcelona y Sao Paulo como metrópolis mundiales.

Del fenómeno global a los procesos locales, este libro de cómodo formato (13,5 por 21 centímetros y 219 páginas - aunque se echa de menos un tamaño de fuente algo mayor-) expresa con suficiencia de puntos de vista y análisis, la diversidad de sus autores. Los cambios en los espacios de las metrópolis son propuestos en este caso, en una vigente tensión centro - periferia, que constituye una condición inmejorable para la caracterización de procesos socio-espaciales, y puesta en visibilidad de nuevos elementos para su análisis. En este sentido las relaciones espaciales vinculadas (centro - periferia), son expuestas en clave de religiones, patrimonio histórico, y vivienda entre otros, posibilitando nuevas formas de entender las dinámicas metropolitanas.

Las nuevas funciones de estas ciudades, en su condición de nodos de poder de orden mundial, configuran un escenario para la recepción de las actividades financieras y de servicios avanzados de la producción. Atrás quedó como evidencia la profesora Carlos, el tiempo en que la industria era el sector económico dominante y centro del dinamismo del sistema capitalista.

En medio de este protagonismo urbano, Barcelona y Sao Paulo emergen día a día. La integración de estas metrópolis al sistema de acumulación y a la red mundial de ciudades cada vez es más notable. Si de alguna manera estas grandes urbes siguen siendo dependientes del mundo global de primer orden y conservan su carácter periférico, también ellas se afirman en la escena internacional como focos de enlace con el sistema mundial.

En este sentido el profesor Carreras, expone la necesidad del análisis ínter escalar, para el entendimiento de las dialécticas fenomenológicas de lo local a lo global, en clave de cultura. El estudio que se propone, pretende mostrar esta construcción - reconstrucción del concepto cultura urbana paulista, manifestada en la apropiación de lo urbano, en la posibilidad de variadas identidades urbanas metropolitanas en la doble vía de aportes y de asunción de elementos. Una aproximación a un mejor conocimiento de quiénes son los ciudadanos metropolitanos, desde una búsqueda de objetivos, valores o experiencias comunes con que identificarlos.

En concordancia propone, el Barrio como primerísimo laboratorio, en un estudio que sin negar la importancia de los aspectos

*Arquitecto. Profesor Titular del Departamento de Arquitectura y Urbanismo en la Universidad de Nariño. Pasto (Colombia), y actualmente doctorando en el programa de Dinámicas Urbanas Y organización del Territorio de la Universidad de Barcelona. E-mail: 
económicos, sociales y políticos que intervienen en los procesos de construcción y reconstrucción urbana, introduzca nuevas variables de análisis que permitan dar cuenta de los puntos de vista de los ciudadanos y de su diversidad, en una multiplicidad de tiempos y espacios. De lo cotidiano a lo global, el barrio y en el la metrópolis, deben ser observadas como un espacio de contemporaneidad de dinámicas distintas que se explican también a escalas distintas.

En un contexto que se dirige cada día más a una economía global, más intensa es la concentración de funciones de poder en un conjunto escaso de lugares.

Determinadas urbes (Madrid, Barcelona, Valencia, y el resto de provincias metropolitanas relacionadas en partes de este estudio) ejercen de manera diferenciada como centros de articulación de economías nacionales, regionales, e internacionales. Las metrópolis, en este sentido, conforman espacios de acumulación global donde se concentran y se materializan los beneficios de los distintos procesos productivos de la nación o región a la que pertenecen. Las actividades más relevantes y las variables económicas, políticas y sociales (en tanto poder político, población y otros) más altas del sistema internacional se contabilizan en estos territorios.

Estos espacios se han dedicado a desarrollar intensamente actividades financieras y de servicios que son inherentes al mismo proceso de acumulación y que les confieren la capacidad de controlar y liderar extensas áreas geográficas en el mundo. No obstante, otras ciudades como Barcelona y Sao Paulo -aun cuando no están consideradas como globales en el sentido estricto del término- asumen funciones especializadas en determinadas áreas y participan activamente en este proceso de acumulación de capital global. Así, las ciudades organizadas jerárquicamente de acuerdo con el papel que desempeñan en el funcionamiento del sistema internacional se constituyen en espacios donde convergen la liquidez, la tecnología, la información y la comercialización de la producción global.

En la relación de las metrópolis en tiempos de globalización con su Estado-nación, se puede evidenciar una dirección opuesta a lo que sucedió en la fase de crecimiento anterior, donde había una fuerte correspondencia entre los sectores económicos más dinámicos y el crecimiento de la economía nacional. El actual modelo acentúa las asimetrías regionales $y$, aun cuando algunas de ellas forman parte del entramado mundial de ciudades, un sector considerable de la población que las habita se encuentra en condiciones de exclusión. La calidad de vida en general no es congruente con el papel que ellas desempeñan en la creación y generación de la riqueza mundial.

Las implicaciones espaciales de estos procesos de concentración de empresas y servicios a la producción en las áreas centrales de las grandes ciudades del mundo, también se ven reflejadas en las demandas de suelo urbano estratégicamente localizado, por parte del capital transnacional, como se ilustra con suficiencia en los casos del Raval de Barcelona, el circuito de la Se, Luz o la Republica en el centro de Sao Paulo, o en el Vale do Anhangabau de la misma ciudad, comprometiendo no solo estructuras urbanas de valoración patrimonial, sino animando la desigualdad y la exclusión como impacto de estas nuevas formas y condiciones para el crecimiento sobre el orden social.

El surgimiento de las nuevas formas de empleo y la consecuente expansión del sector social de altos ingresos, permite elevados y sofisticados niveles y pautas de consumo, que son oportunamente relacionados explicando al menos parcialmente, procesos de gentrificación central y surgimiento de nuevas urbanizaciones en los espacios perimetrales.

Con gran certeza se podía afirmar que Barcelona y Sao Paulo, experimentan un intento de organización dicotómico, en un espacio urbano fragmentado. Una negociación (conflicto) entre las pervivencias de la ciudad industrial de "lógica fordista" en vías de extinción expresadas 


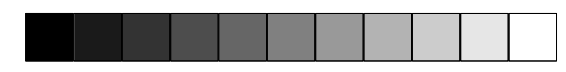

Barcelona São Paulo, tan lejos tan cerca. A propósito del libro Barcelona y

en la creciente desestructuracion socio territorial, y la emergencia de espacios centrales y periféricos de orden postindustrial y dinámicas postmodernas.

Así, estas metrópolis se desarrollan como un escenario de múltiples autorías entre ideas opuestas y aparentemente irreconciliables. Una metrópolis global resulta ser una especie de enclave que concentra y asume actividades de primer orden en la creación y generación de riqueza del país, de la región y del sistema de acumulación capitalista mundial. Así lo exhibe la zona del centro financiero de la Avenida Paulista o Diagonal Mar. Por otro lado, en un espacio casi inmediato, vemos un mundo de exclusión que vive la parte más desafortunada de la ciudad, atrapado en la pobreza, en las actividades económicas informales, y en la marginación.
Queda entonces planteado el desafío de animar la continuidad de los estudios que fundamenten una reflexión sobre cómo llegan estos procesos descritos a unas metrópolis periféricas, y como se podría enfrentar y gestionar, desde los ámbitos políticos locales, las consecuencias de este nuevo modelo de crecimiento controlado globalmente y que agudiza la exclusión social y la desigualdad socio-territorial.

Finalmente y volviendo a su titulo "... a la hora de la globalización.", quizás lo más vigente e importante de este libro no sean solo sus afirmaciones y certezas, sino las preguntas que deja sin responder y las líneas investigativas e interpretativas que abre. Después de leer el libro, las ciudades emergen mucho más densas en contenidos y complejas en estructura, tal como los millones de personas que las habitan.

Trabalho enviado em janeiro de 2007

Trabalho aceito em janeiro de 2007 
